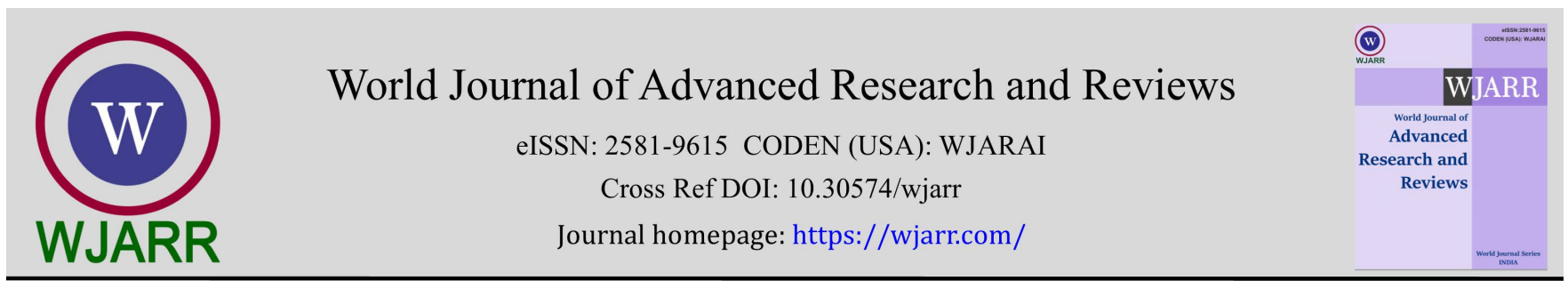

(RESEARCH ARTICLE)

\title{
Effectiveness of prevention of mother to child transmission of HIV in Bowen University Teaching Hospital, 0yo State, Nigeria
} \author{
Moyosore Adebisi ${ }^{2}$ \\ ${ }^{1}$ Department of Nursing Science, Bowen University, Iwo. Osun State, Nigeria. \\ 2 Department of Clinical Nursing, University College Hospital, Ibadan. Oyo State. Nigeria.
}

Taiwo Omotayo Dosumu 1, *, Oluwaseyi Isaiah Olabisi ${ }^{1}$, Grace Oluwaranti Ademuyiwa ${ }^{1}$ and Temitayo

World Journal of Advanced Research and Reviews, 2021, 09(02), 134-140

Publication history: Received on 15 January 2021; revised on 17 February 2021; accepted on 19 February 2021

Article DOI: https://doi.org/10.30574/wjarr.2021.9.2.0057

\begin{abstract}
Mother-to-child transmission (MTCT) of Human Immunodeficiency Virus (HIV) is the most significant route of HIV infection in children. Over $90 \%$ of HIV infections in children are acquired through the mother-to-child transmission route. This study aimed to evaluate the effectiveness of prevention of mother to child transmission (PMTCT) of HIV interventions. It employed a retrospective approach. Records of HIV positive pregnant women who registered and received ANC between January 1st 2015 to December 31st 2018 and HIV exposed infants followed-up for 6 weeks until HIV status was determined by DNA polymerase chain reaction techniques were collected and analysed. 87 pregnant women were HIV positive during the 4 years period, among these group, only 80 had their babies followed up till 6 weeks to determine HIV status by DNA polymerase chain reaction. There were three set of twins making a total of 83 exposed infants. The overall MTCT rate was $4.8 \%$, maternal and infant ART was found to have significant influence on mother to child transmission of HIV with $\chi 2=41.41, \mathrm{P}<0.001$ and $\chi 2=34.554, \mathrm{P}<0.001$ respectively. Mode of delivery and infant feeding practice were statistically not significantly related to mother to child transmission of HIV with $\chi 2=3.92$, $\mathrm{P}=0.41$ and $\chi 2=1.859, \mathrm{P}=0.173$ respectively. Though this facility achieved the goal of reducing the rate of HIV mother to child transmission down to less than $5 \%$, there is still need to strengthen service provision and follow up to conform to global plan for the elimination of new HIV infections among children.
\end{abstract}

Keywords: Antiretroviral therapy; Effectiveness; Human Immunodeficiency Virus; Mother to child transmission; Prevention of mother to child transmission

\section{Introduction}

Human Immunodeficiency Virus (HIV) is a global public health crisis with sub Saharan Africa having a disproportionately high burden of the epidemic [1]. According to UNAIDS, there were 37.9 million People living with HIV/AIDS across the globe in 2018. Of these, 36.2 million were adults and 1.7 million were children ( $<15$ years old). An estimated 1.7 million individuals worldwide became newly infected with HIV in 2018 of these are 160, 000 infections among children ages 0-14 [2]. Nigeria has the second largest HIV epidemic in the world [3]. An estimate of 1.9 million people in Nigeria were living with HIV in 2018. Recent drops in prevalence estimates for the country has been attributed to better surveillance [4].

Mother-to-child transmission (MTCT) of Human Immunodeficiency Virus (HIV) is the most significant route of HIV infection in children. Over $90 \%$ of HIV infections in children are acquired through the mother-to-child transmission (MTCT) route [5]. A woman with HIV who had no prevention of mother to child transmission (PMTCT) intervention has

\footnotetext{
${ }^{*}$ Corresponding author: Taiwo Omotayo Dosumu

Department of Nursing Science, Bowen University, Iwo. Osun State, Nigeria.

Copyright (C) 2021 Author(s) retain the copyright of this article. This article is published under the terms of the Creative Commons Attribution Liscense 4.0.
} 
a $30-45 \%$ chance of passing the virus to her baby during pregnancy, labour, delivery as well as during breast feeding [6]. Nigeria contributes over a quarter (26.9\%) of all cases of mother-to-child transmission (MTCT) of HIV in the world $[7]$.

To achieve the goal of United Nations of elimination of new HIV infections, a program of prevention of mother-to-child transmission (PMTCT) was launched. With appropriate interventions which include use of antiretroviral (ARV) drugs, obstetric interventions and modification of infant feeding, MTCT rates have been reduced to $<2 \%$ in some countries [8][9]. This has significantly reduced the incidence of paediatric HIV/AIDS and associated morbidity and mortality in those countries. The rate of mother to child transmission in Nigeria has remained high with an estimate of $22 \%$ in 2016 [10][11]. As such, reducing mother-to-child transmission remains a major target area.

The national PMTCT programme in Nigeria commenced in 2002 with supports from WHO and UNICEF [12]. The applicability and efficacy of PMTCT programs in Bowen University Teaching Hospital is scarcely known hence this study is instituted to determine the effectiveness of Prevention of Mother to Child Transmission of HIV in Bowen University Teaching Hospital, Ogbomoso, Oyo State.

\subsection{Study Objectives}

The broad objective is to evaluate the effectiveness of prevention of mother to child transmission (PMTCT) of HIV interventions.

\subsection{Specific objectives include}

- To determine the rate of mother to child transmission of HIV

- To determine the effect of ART (maternal and infant) on MTCT of HIV

- To determine the effect of delivery mode on MTCT of HIV

- The determine the effect of infant feeding type on MTCT of HIV

\section{Material and methods}

\subsection{Research Design}

This study was a retrospective longitudinal study targeting mother-infant pair seeking care at Bowen University Teaching Hospital.

\subsection{Study Population}

The study covered HIV positive pregnant women who registered and received ANC between January $1^{\text {st }} 2015$ and December 31 2018 in Bowen University Teaching Hospital, Ogbomosho and infants followed-up for 6 weeks until HIV status was determined.

\subsection{Method of data collection}

Records of HIV positive pregnant women who registered and had antenatal care (ANC) in the period January 1 st, 2015 to December 31 ${ }^{\text {st }}, 2018$, delivered in or outside hospital and whose HIV-exposed babies were followed-up to 6 weeks of age when HIV status was determined by DNA polymerase chain reaction techniques were collected and analyse. Motherinfant pair data was extracted from PMTCT registers and patients' medical files.

The variables collected include total number of HIV positive pregnant women registered in the 4 years of the study, maternal age, employment status, type of ARV regimen, time of commencement, mode of delivery, infant feeding practice and infant HIV status.

\subsection{Method of Data Analysis}

Data was entered and processed using SPSS version 21. Descriptive statistics using frequency and percentages were also used, effect of various interventions on MTCT of HIV was determined using Pearson chi square test of significance.

\subsection{Ethical consideration}

Ethical approval for the study was obtained from Ethical review committee of Bowen University Teaching Hospital. 


\subsection{Confidentiality of Data}

Confidentiality of information gotten was maintained as clients' names and personal details were excluded. Data collected was used for research purpose only.

\subsection{Non-Maleficence to Participants}

This study was not detrimental to the clients in any way.

\section{Results}

Table 1 Socio demographic characteristics of study population.

\begin{tabular}{|l|l|l|}
\hline Variable & Frequency & Percentage \\
\hline Age (years) & & \\
$20-24$ & 2 & 2.5 \\
$25-29$ & 7 & 8.75 \\
$\geq 30$ & 71 & 88.75 \\
\hline Tribe & Mean 2.86 & \\
Yoruba & & \\
Hausa & 74 & 92.5 \\
Ibo & 1 & 1.25 \\
Others & 1 & 1.25 \\
\hline Occupation & 4 & 5.0 \\
Civil servant & & \\
Trading & 22 & 27.5 \\
Unemployed & 40 & 50 \\
Others & 12 & 15 \\
\hline Education & 6 & 7.5 \\
Primary or less & & \\
Secondary & 18 & 22.5 \\
Tertiary & 40 & 50.0 \\
\hline Religion & 22 & 27.5 \\
Christianity & & \\
Islam & 69 & 86.25 \\
Traditional & 10 & 12.5 \\
\hline Marriage setting & 1 & 1.25 \\
Monogamy & 73.5 \\
Polygamy & 6 & 1.25 \\
Single parent & 125.5 \\
\hline Parity & 35 & \\
0 & & 41.25 \\
1-2 & & \\
$>2$ & & \\
\hline & & \\
\hline
\end{tabular}

Table 1 revealed that majority were 30 years and above with mean age of 2.86 , were Yoruba with $92.5 \%$. Half of the population were traders with secondary level of education. More than three quarter were Christians and in monogamy setting. 
Table 2 Rate of mother to child transmission of HIV

\begin{tabular}{|l|l|l|}
\hline MTCT & Frequency & Percentage \\
\hline Negative & 79 & 87.78 \\
\hline Positive & 4 & 4.44 \\
\hline Not followed up & 7 & 7.78 \\
\hline Total & 90 & 100 \\
\hline
\end{tabular}

Table 2 above shows that of the total 90 infants only 83 were followed up till 6 weeks until HIV status was determined by DNA PCR. Of the 83, only 4 were HIV positive with MTCT rate of $4.82 \%$

Table 3 Effect of ART (MATERNAL) on MTCT of HIV

\begin{tabular}{|l|l|l|l|l|l|}
\hline \multicolumn{2}{|l|}{ Maternal ART } & \multicolumn{2}{l|}{ Infant HIV Status } & \multirow{2}{*}{ Total } & $\begin{array}{l}\text { Pearson chi } \\
\text { square }\end{array}$ \\
\cline { 2 - 5 } & Negative & Positive & & 41.41 \\
\hline \multirow{3}{*}{ ART Before pregnancy } & 28 & 0 & 28 & $\mathrm{p}<0.001$ \\
\cline { 2 - 5 } & ART during pregnancy & 41 & $1(25 \%)$ & 42 & \\
\cline { 2 - 5 } & ART during delivery & 0 & $1(25 \%)$ & 1 & \\
\cline { 2 - 5 } & ART during pregnancy/delivery & 5 & 0 & 5 & \\
\cline { 2 - 5 } & ART after delivery & 0 & $1(25 \%)$ & 1 & \\
\cline { 2 - 5 } & No ART & 2 & $1(25 \%)$ & 3 & \\
\hline \multicolumn{2}{|l|}{ Total } & 76 & 4 & 80 & \\
\hline
\end{tabular}

The table above shows the effect of maternal ART on the rate of mother to child transmission of HIV. None of the infant of mothers who started ART before pregnancy and those who had ART during pregnancy and delivery was positive. One each of mothers who started ART during pregnancy, started ART during delivery, started ART after delivery and mothers who didn't take ART at all was positive. Mothers who were on ART were statistically less likely to have HIV infected infants $(\chi 2=41.41, \mathrm{P}<0.001)$

Table 4 Effect of INFANT ART on MTCT of HIV

\begin{tabular}{|l|l|l|l|l|}
\hline \multirow{2}{*}{ Infant ART } & \multicolumn{2}{|l|}{ Infant HIV Status } & \multirow{2}{*}{ Total } & \multirow{2}{*}{ Pearson Chi Square } \\
\cline { 2 - 4 } & Negative & Positive & & \\
\hline \multirow{2}{*}{$\begin{array}{l}\text { Infant ART } \\
\text { No Infant ART }\end{array}$} & 74 & $0(0 \%)$ & 74 & 34.554 \\
\hline Total & 5 & $4(100 \%)$ & 9 & $\mathrm{p}<0.001$ \\
\hline
\end{tabular}

The table above shows that only infants who did not receive ART prophylaxis were positive. Hence, infants who were on ART were statistically less likely to be HIV positive $(\chi 2=34.554, \mathrm{P}<0.001)$. 
Table 5 Effect of Delivery mode on MTCT of HIV

\begin{tabular}{|c|c|c|c|c|}
\hline \multirow[t]{2}{*}{ Delivery mode } & \multicolumn{2}{|c|}{ Infant HIV Status } & \multirow[t]{2}{*}{ Total } & \multirow{2}{*}{$\begin{array}{l}\text { Pearson } \\
\text { Chi } \\
\text { Square }\end{array}$} \\
\hline & Negative & Positive & & \\
\hline \multirow{3}{*}{$\begin{array}{l}\text { EMC/S } \\
\text { ELC/S } \\
\text { SVD }\end{array}$} & 3 & $1(25 \%)$ & 4 & 3.923 \\
\hline & 10 & $0(0 \%)$ & 10 & $\mathrm{P}=0.141$ \\
\hline & 63 & $3(75 \%)$ & 66 & \\
\hline Total & 76 & 4 & 80 & \\
\hline
\end{tabular}

Table 5 above shows that none of the infants of mothers who had elective caesarean section was HIV positive, $25 \%$ of those whose mother had emergency caesarean section and $75 \%$ whose mothers had spontaneous vagina delivery were positive. Mode of delivery was statistically not significantly related to mother to child transmission of HIV $(\chi 2=3.92$, $\mathrm{P}=0.41)$

Table 6 Effect of Infant Feeding option on MTCT of HIV

\begin{tabular}{|c|c|c|c|c|}
\hline \multirow[t]{2}{*}{ Infant Feeding } & \multicolumn{2}{|c|}{ Infant HIV Status } & \multirow{2}{*}{$\begin{array}{l}\text { Tota } \\
\text { l }\end{array}$} & \multirow{2}{*}{$\begin{array}{l}\text { Pearson } \\
\text { Square }\end{array}$} \\
\hline & Negative & Positive & & \\
\hline Exclusive & 71 & $3(75 \%)$ & 74 & 1.859 \\
\hline $\begin{array}{l}\text { Formula } \\
\text { Mixed feeding }\end{array}$ & $\begin{array}{l}5 \\
0\end{array}$ & $\begin{array}{l}1(25 \%) \\
0\end{array}$ & $\begin{array}{l}6 \\
0\end{array}$ & $\mathrm{P}=0.173$ \\
\hline Total & 76 & 4 & 80 & \\
\hline
\end{tabular}

The table above shows that of the 80 women, only 74 practiced exclusive breastfeeding and out of these 3 (75\%) of their infants were HIV positive. Of the 6 women that practice formula feeding in the first six month of birth, only $1(25 \%)$ of their infant was HIV positive. None of the women practiced mixed feeding. Statistical analysis shows that infant feeding practice has no effect on mother to child transmission of HIV $(\chi 2=1.859, \mathrm{P}=0.173)$.

\section{Discussion}

A total number of 87 pregnant HIV positive women presented during this period, three of the women had twin gestation and only 80 followed up their infant until 6 weeks post-delivery when HIV status was determined by DNA PCR. This study revealed a mother to child transmission rate of 4.8\% from January 2015 to December 2018. This rate is quite higher to what was reported by Agboghoroma, Audu, Iregbu [13]. In a similar study in Abuja where the rate was 2.4\% and $3.2 \%$ in another study [14]. The rate form this study is lower than what was reported in a study in Angola with of MTCT of HIV been 13.89\% [15] and 7.7\% MTCT rate in a study in Ethiopia [16]. This could be due to the promotion of PMTCT options in the hospital, increased level of awareness via media and increased in the number of facilities rendering PMTCT services in the country.

Maternal and infant ART has significant influence on mother to child transmission of HIV with $\chi 2=41.41, P<0.001$ and $\chi 2=34.554, \mathrm{P}<0.001$ respectively. None of the infant of mothers who started ART before pregnancy and those who had ART during pregnancy and delivery was positive. Only one each of mothers who started ART during pregnancy, started ART during delivery, started ART after delivery and mothers who didn't take ART at all was positive and only infants who did not receive ART prophylaxis were positive. This is comparable to result of a study carried out in North Central Nigeria [17], where mothers who were on ART were statistically less likely to have HIV-infected infants $(\chi 2=54.71$, $\mathrm{P}<0.00$ ). According to the report of a study in Nigeria [18], the prevalence of MTCT reduces when both mother and baby received a form of chemoprophylaxis for PMTCT. This indicates the importance of identifying HIV status before pregnancy or early in pregnancy so that prompt intervention can be put in place 
Mode of delivery was statistically not significantly related to mother to child transmission of HIV $(\chi 2=3.92$, $\mathrm{P}=0.41)$, though none of the women who had elective caesarean section was HIV positive. This is similar with findings in Abuja Nigeria [19], where women who were delivered by CS had lowered MTCT compared with those who had a vaginal delivery. Elective CS was however associated with lower MTCT transmission rates compared with emergency CS. Also similar to this, is the report of a study in Guangdong province [20], where it was concluded that delivery mode might not be relative to HIV MTCT. This is in contrast to what was reported in a study in Nigeria [21], where the mode of delivery (caesarean section vs SVD) was statistically significant $(\mathrm{P}<0.00)$

Of the 80 HIV positive women from this study, only 74 practiced exclusive breastfeeding and out of these 3 (75\%) of their infants were HIV positive. Of the 6 women that practice formula feeding in the first six month of birth, only $1(25 \%)$ of their infant was HIV positive. None of the women claimed to have practiced mixed feeding. This corresponds to World Health Organisation guidelines which recommend the national authorities to promote one infant practice among mothers with HIV, either exclusive breastfeeding while ARV drugs are provided or avoiding all breast milk [22][23]. This reveals a good understanding of the risk of mixed feeding. Statistical analysis shows that infant feeding practice has no effect on mother to child transmission of HIV $(\chi 2=3.92, \mathrm{P}=0.41)$. The breastfeeding rate $(92.5 \%)$ in this study was higher than findings from other African studies [24]. This reflects cultural practices supporting breastfeeding in Nigeria. However, with the higher rate of MTCT of HIV associated with exclusive breastfeeding, there is possibility that some of the mothers practiced mixed feeding. There is need to increase level of awareness of mothers on the concept of exclusive breastfeeding.

\section{Conclusion}

The rate of mother to child transmission of HIV in Bowen University Teaching Hospital Ogbomosho from January 2015 to December 2018 is $4.8 \%$. All the infant who were positive were those who did not receive prophylasix ART, hence it is important to strengthen the implementation of PMTCT program to increase the availability and acceptability of interventions. Although, this facility achieve the expectant goal of reducing the rate of HIV MTCT down to less than 5\% with PMTCT interventions in place, there is still need to strengthen service provision and follow up to conform to global plan for the elimination of new HIV infections among children and keeping their mothers alive.

\section{Compliance with ethical standards}

\section{Acknowledgments}

Sincere appreciation goes to the Management and Ethical review committee of Bowen University Teaching Hospital for the privilege and support to carry out this work. Special thanks to the record department of Bowen for assisting with the records of clients.

\section{Disclosure of conflict of interest}

There are no potential conflicts of interest in this study

\section{Statement of informed consent}

Since the study was a retrospective study, no informed consent was taken

\section{References}

[1] World Health Organization. Guidance on Global Scale up of the Prevention of PMTCT of HIV. Toward Universal access for Eliminating HIV and AIDS among children. WHO, Geneva. 2014.

[2] UNAIDS. Global HIV \& AIDS statistics fact sheet. 2019.

[3] NACA. National Strategic Framework on HIV and AIDS. 2017 -2021.

[4] PEPFAR. Large National Survey Shows Smaller HIV Epidemic in Nigeria than Once Thought and Highlights Key Gaps toward Reaching HIV Epidemic Control. 2019.

[5] UNAIDS. Global AIDS Response Progress Reporting. Geneva. 2011. 
[6] World Health Organization (WHO). Antiretroviral Drugs for Treating Pregnant Women and Preventing HIV Infection in Infants: Recommendations for a Public Health Approach; World Health Organization: Geneva, Switzerland. 2012.

[7] Joints United Nations Programme on AIDS (UNAIDS). Miles to Go: West and Central Africa. The response to HIV in Western and Central Africa. 2018.

[8] Townsend C, Cortina-Borja M, Peckham C, Lyall H, De Ruiter A, Tookey P. Very low risk of mother-to-child transmission of HIV in women on HAART achieving viral suppression in the UK and Ireland. AIDS. 2008; 22: 97381.

[9] Agboghoroma OC. Prevention of mother-to-child transmission of HIV/AIDS Confronting the Challenge of Reproductive Health in Africa: A Textbook for Students and Development Practitioners. Okonofua, Benin: WHARC. 2014; 347-68.

[10] National Bureau of Statistics (NBS) and United Nations Children's Fund (UNICEF). Multiple Indicator Cluster Survey 2016-17, Survey Findings Report . 2017.

[11] Joints United Nations Programme on AIDS (UNAIDS). Miles to Go: West and Central Africa. The response to HIV in Western and Central Africa. 2018.

[12] Federal Ministry of Health. Federal Government of Nigeria. National Guidelines on Prevention of Mother to Child Transmission (PMTCT) of HIV in Nigeria. 2017.

[13] Agboghoroma CO, Audu LI, Iregbu KC. Effectiveness of prevention of mother-to-child transmission of HIV program in Abuja, Nigeria. J HIV Hum Reprod [serial online]. 2015; 3: 7-13.

[14] Mukhtar-Yola M, Otuneye AT, Mairami AB, Wey Y, Nwatah V, Audu LI. Audit of prevention of mother-to-child transmission programme interventions in HIV-Exposed children at national hospital, Abuja, Nigeria. Niger Postgrad Med J 2018; 25: 27-31.

[15] Bing L, Qingguo Z, Xiaozhuang Z, Li W, Tingting C, Zhijiang L, Longchang X, Shouyi Y. Effectiveness of a prevention of mother-to-child HIV transmission program in Guangdong province from 2007 to 2010 BMC Public Health. 2013; 13: 591.

[16] Abdula M, Zeleke T, Shibeshi W. Assessment of Effectiveness of Prevention of Mother to Child Transmission of Human Immunodeficiency Virus In Asella Hospital, Ethiopia J Clin Pharm. 2017; 19(3): 198-206.

[17] Oleribe 00, Enenche E, Udofia D, Ekom E, Osita-Oleribe PI, Kim JU, Taylor-Robinson SD. Assessment of the effectiveness of PMTCT program in eight service delivery points in North Central Nigeria. Dovepress. 2018; 10: $253-259$.

[18] Chukwuemeka IK, Fatima CI, Kabiru ZK, Olukayode O. The impact of a HIV prevention of mother to child transmission program in a Nigerian early infant diagnosis centre. Niger Med J. 2014; 55: 204-8.

[19] Agboghoroma CO, Audu LI, Iregbu KC. Effectiveness of prevention of mother-to-child transmission of HIV program in Abuja, Nigeria. J HIV Hum. 2015; 3: 7-13.

[20] Bing L, Qingguo Z, Xiaozhuang Z, Li W, Tingting C, Zhijiang L, Longchang X, Shouyi Y. Effectiveness of a prevention of mother-to-child HIV transmission program in Guangdong province from 2007 to 2010 BMC Public Health. 2013; 13: 591.

[21] Oleribe 00, Enenche E, Udofia D Ekom E, Osita-Oleribe PI, Kim JU, Taylor-Robinson SD. Assessment of the effectiveness of PMTCT program in eight service delivery points in North Central Nigeria. Dovepress. 2018; 10: $253-259$.

[22] The World Health Organization. Updates on HIV and Infant Feeding. 2018.

[23] Ciaranello AL, Park JE, Ramirez-Avila L, Freedberg KA, Walensky RP, Leroy V. Early infant HIV-1 diagnosis programs in resource-limited settings: opportunities for improved outcomes and more cost-effective interventions. BMC Med. 2011; 9(1): 59.

[24] Goga AE, Dinh TH, Jackson DJ. First population-level effectiveness evaluation of a national programme to prevent HIV transmission from mother to child, South Africa. J Epidemiol Community Health. 2015; 69(3): $240-248$. 